\title{
Low variation in ribosomal DNA and internal transcribed spacers of the symbiotic fungi of leaf-cutting ants (Attini: Formicidae)
}

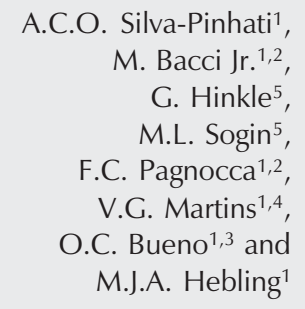

\author{
${ }^{1}$ Centro de Estudos de Insetos Sociais, and Departamentos de \\ ${ }^{2}$ Bioquímica e Microbiologia, and ${ }^{3}$ Biologia, Instituto de Biociências, \\ Universidade Estadual Paulista, Rio Claro, SP, Brasil \\ ${ }^{4}$ Departamento de Fonoaudiologia, Universidade Estadual Paulista, Marília, SP, Brasil \\ ${ }^{5}$ Josephine Bay Paul Center for Comparative Molecular Biology and Evolution, \\ Marine Biological Laboratory, Woods Hole, MA, USA
}

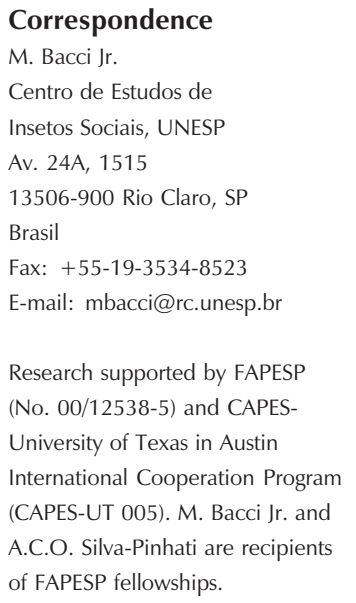

Received October 20, 2003 Accepted June 22, 2004

\section{Abstract}

Leaf-cutting ants of the genera Atta and Acromyrmex (tribe Attini) are symbiotic with basidiomycete fungi of the genus Leucoagaricus (tribe Leucocoprineae), which they cultivate on vegetable matter inside their nests. We determined the variation of the $28 \mathrm{~S}, 18 \mathrm{~S}$, and 5.8S ribosomal DNA (rDNA) gene loci and the rapidly evolving internal transcribed spacers 1 and 2 (ITS1 and ITS2) of 15 sympatric and allopatric fungi associated with colonies of 11 species of leafcutter ants living up to $2,600 \mathrm{~km}$ apart in Brazil. We found that the fungal rDNA and ITS sequences from different species of ants were identical (or nearly identical) to each other, whereas 10 GenBank Leucoagaricus species showed higher ITS variation. Our findings suggest that Atta and Acromyrmex leafcutters living in geographic sites that are very distant from each other cultivate a single fungal species made up of closely related lineages of Leucoagaricus gongylophorus. We discuss the strikingly high similarity in the ITS1 and ITS2 regions of the Atta and Acromyrmex symbiotic $L$. gongylophorus studied by us, in contrast to the lower similarity displayed by their non-symbiotic counterparts. We suggest that the similarity of our L. gongylophorus isolates is an indication of the recent association of the fungus with these ants, and propose that both the intense lateral transmission of fungal material within leafcutter nests and the selection of more adapted fungal strains are involved in the homogenization of the symbiotic fungal stock.

\section{Introduction}

The tribe Attini consists of approximately 200 species of ants living in symbiosis with three distinct groups of microorganisms, in what has been called 'one of the most complex symbiotic association discovered in nature'
Key words

- Atta

- Acromyrmex

- Internal transcribed spacer

- Leaf-cutting ants

- Leucoagaricus

- Leucoagaricus gongylophorus
(1). These microorganisms include symbiotic basidiomycete fungi, which the ants utilize as food source, a parasite fungus of the genus Escovopsis, which attacks the symbiotic fungal culture, and actinomycete bacteria, which grow in the ants' body and produce antibiotics that are active against Escovopsis (1). 
There are 13 genera of attines $(2,3)$, the most derived being the leafcutter ants of the genera Atta and Acromyrmex, which are the dominant herbivores in the Neotropical region between latitude $12^{\circ}$ North and $33^{\circ}$ South $(4,5)$. This dominance results from the metabolic integration between the symbionts (6-9), which has been established during 50 million years of co-evolution $(10,11)$.

To understand the processes involved in the association between leaf-cutting ants and symbiotic fungi, the diversity within each member of the symbiont pair needs to be characterized, but although the taxonomy of ants is well advanced (2), the taxonomy, and hence the diversity, of their symbiotic fungi has not yet been completely elucidated. Basidiocarps collected from nests of Atta species have been named Leucocoprinus gongylophorus (12), Leucoagaricus gongylophorus (13) and Leucoagaricus weberi (14), but paired tests with mycelia suggest that some Atta and Acromyrmex ants cultivate a single species of fungus (15).

The multiple fungal species versus single species theories have more than taxonomic implications, being also related to the modes of fungal transmission within leafcutter colo-

Table 1. Leucoagaricus isolates obtained from the nests of leaf-cutting ants.

\begin{tabular}{llll}
\hline Isolate code & $\begin{array}{c}\text { Location } \\
\text { in Brazil }\end{array}$ & Ant & $\begin{array}{l}\text { Physical state } \\
\text { of the culture }\end{array}$ \\
\hline $\mathrm{A}$ & Rio Claro & Atta laevigata & Mycelial \\
$\mathrm{B}$ & Rio Claro & Atta sexdens rubropilosa & Mycelial \\
$\mathrm{C}$ & Rio Claro & Acromyrmex crassispinus & Mycelial \\
$\mathrm{D}$ & Rio Claro & Acromyrmex hispidus fallax & Mycelial \\
$\mathrm{E}$ & Rio Claro & Acromyrmex hispidus fallax & Basidiocarp \\
$\mathrm{F}$ & Botucatu & Atta capiguara & Mycelial \\
$\mathrm{G}$ & Botucatu & Atta bispherica & Mycelial \\
$\mathrm{H}$ & Botucatu & Acromyrmex rugosus & Mycelial \\
$\mathrm{I}$ & Ubatuba & Acromyrmex disciger & Mycelial \\
$\mathrm{J}$ & Viçosa & Atta sexdens rubropilosa & Mycelial \\
$\mathrm{K}$ & Viçosa & Acromyrmex subterraneus molestans & Mycelial \\
$\mathrm{L}$ & Viçosa & Acromyrmex subterraneus molestans & Mycelial2 \\
$\mathrm{M}$ & Viçosa & Acromyrmex subterraneus molestans & Basidiocarp2 \\
$\mathrm{N}$ & Almeirim & Atta cephalotes & Mycelial \\
$\mathrm{O}$ & Almeirim & Acromyrmex laticeps & Mycelial \\
\hline
\end{tabular}

1,2Basidiocarp and mycelial states collected from the same ant's nest. nies. Vertical transmission occurs when queen ants leave their parent nest carrying the symbiotic fungus, which is then cultured by the newly founded colony (16). It has been proposed that vertical transmission has selected host-specific lineages of symbiotic fungi in leafcutter nests during the past 23 million years (10), so that the exclusively vertical transmission of fungal cultures within leafcutters is consistent with the existence of multiple symbiotic fungal species. On the other hand, the culturing of the same fungal species by Atta and Acromyrmex ants may indicate lateral transmission of fungal lineages. In laboratory nests, lateral transmission of symbiotic fungal strains has been induced between and within species of basal attines of the genus Cyphomyrmex (17) as well as two Acromyrmex species (18) and also seems occasionally to occur in nature (18-21).

In the present paper, we provide new information on the systematics of Leucoagaricus symbiotic fungi, which we obtained by sequencing the $28 \mathrm{~S}, 18 \mathrm{~S}$ and $5.8 \mathrm{~S}$ rDNA loci and internal transcribed spacers 1 and 2 (ITS1 and ITS2) of two basidiocarp and thirteen mycelial fungal isolates collected from the nests of attine ants located in several geographic regions of Brazil between latitudes $1.52^{\circ}$ and $23.43^{\circ}$ South. Our results suggest that all the isolates studied belong to the species Leucoagaricus gongylophorus and that lateral transmission was a common event through which selected lineages of the symbiotic fungus quickly proliferated in nests of many of the higher attine ants living in the tropical Americas.

\section{Material and Methods}

\section{Fungal isolates and culture conditions}

The Leucoagaricus isolates (Table 1) were collected as basidiocarps or as mycelial states from the nests of Atta and Acromyrmex ants from July 1985 to December 2001 from 
the geographic sites shown in Figure 1. The basidiocarp collected from Acromyrmex hispidus fallax was identified as Leucoagaricus gongylophorus Heim (22). For the isolation of the mycelial form of the fungus from the fungus garden we used yeast nitrogen base glucose chloramphenicol (YNBGC) agar, which increases the efficiency of isolation of this fungus (Silva-Pinhati ACO, Bacci M, Siqueira CG, Silva A, Pagnocca FC, Bueno $\mathrm{OC}$ and Hebling MJA, unpublished results) and consists of yeast nitrogen base medium (YNB, Difco 0392-15-9, Detroit, MI, USA) supplemented with $5 \mathrm{~g} / \mathrm{l}$ glucose (product number 108342, Merck, Darmstadt, Germany), $17 \mathrm{~g} / \mathrm{l}$ agar (Merck, product number 1.01614), $0.1 \mathrm{~g} / 1$ chloramphenicol (product number C-0378, Sigma, St. Louis, MO, USA), and sufficient $2 \mathrm{M} \mathrm{NaOH}$ to adjust the $\mathrm{pH}$ to 6.0. For maintenance we used YNB-glucose agar (i.e., YNBG without chloramphenicol). The fungus garden material, collected from the underground nests of different ant species, was incubated in the dark at $25^{\circ} \mathrm{C}$ and $80 \%$ humidity for 10 to 20 days on Petri dishes containing worker ants, which cleaned the garden material by removing soil fragments to a different part of the dish. When white mycelial spots of the fungal symbiont appeared on the leaf material some of the mycelium was collected using an aseptic technique and transferred to YNBGC agar on Petri dishes where it was incubated at $25^{\circ} \mathrm{C}$ in the dark for 30 days. Alternatively, the fungus garden material from underground nests was collected and immediately plated onto YNBGC agar and incubated at $25^{\circ} \mathrm{C}$ in the dark for 30 days. In both cases, after 30 days of cultivation on YNBGC agar the fungal isolates were subcultured to YNBG agar and cultured for a further 60 days, with the hyphae showing swollen tips (gongylidium), which are a distinctive characteristic of the symbiotic fungi of higher attine ants (5). The experiments described in this paper were carried out after two months to ten years of storage. When needed for DNA extraction, mycelium was transferred to fresh YNBG agar and grown for 30 days, after which approximately $100 \mathrm{mg}$ mycelium was processed as described below.

\section{DNA extraction}

Fungal mycelium was disrupted by placing $100 \mathrm{mg}$ mycelium in a $1.5-\mathrm{ml}$ microcentrifuge tube, freezing the tube and contents in liquid nitrogen, adding $0.5 \mathrm{ml}$ ice-cold TE buffer, $\mathrm{pH}$ 8.6, containing $0.1 \%(\mathrm{w} / \mathrm{v})$ SDS and homogenizing the mycelia with a plastic pestle that fitted inside the tube. The nucleic acid was purified using buffered phenol, followed by a buffered phenol:chloroform mixture $(1: 1, \mathrm{v} / \mathrm{v})$ and finally pure chloroform. Total nucleic acids were precipitated with ethanol and sodium acetate, washed with ethanol and dissolved in $100 \mu \mathrm{TE}$ buffer.

\section{Amplification of ribosomal DNA and internal transcribed spacer regions}

PCR amplification was carried out in a $100-\mu 1$ reaction mixture using $100 \mathrm{ng}$ fungal

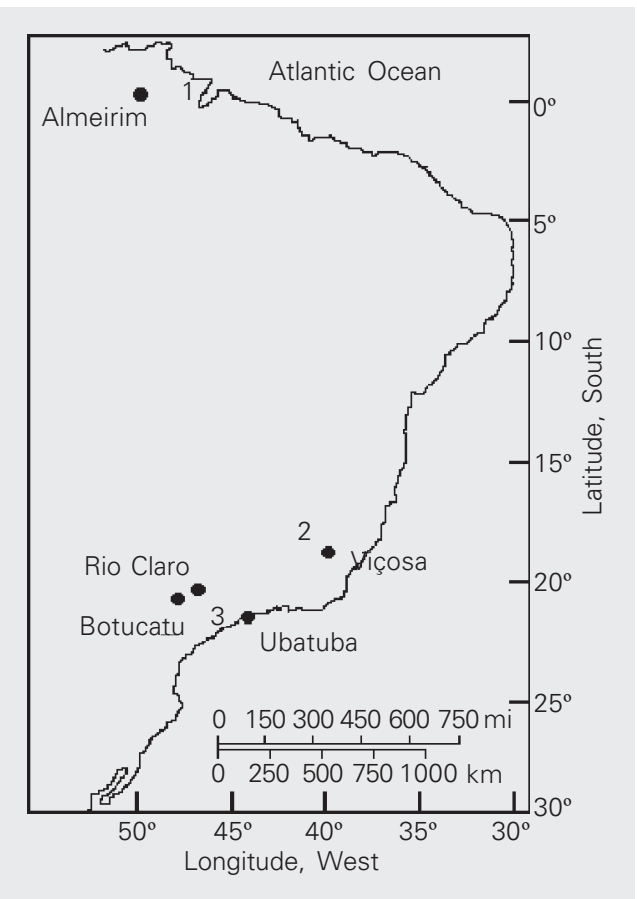

Figure 1. The five geographic sites (Almeirim, Rio Claro, Botucatu, Viçosa, Ubatuba) from which the fungal isolates were collected. The numbers in the map indicate locations of state capitals around each collection site: (1) Macapá (AM); (2) Belo Horizonte (MG); (3) São Paulo (SP). 
genomic DNA and 6 pmol each of primers F5.8S (5'-GGATCACTCGGCTCRTGNRTC GATGAAG-3') and R-635 (5'-GGTCCGT GTTTCAAGACGG-3'). The amplification protocol consisted of initial denaturation at $94^{\circ} \mathrm{C}$ for $3 \mathrm{~min}$, followed by 30 PCR amplification cycles of $94^{\circ} \mathrm{C}$ for $10 \mathrm{~s}, 37^{\circ} \mathrm{C}$ for 1 $\min$ and $72^{\circ} \mathrm{C}$ for $3 \mathrm{~min}$. The amplification produced fragments of approximately $1 \mathrm{~kb}$ comprising the $5.8 \mathrm{~S}$ gene, the ITS2 region and $0.6 \mathrm{~kb}$ of the $28 \mathrm{~S}$ gene. The same procedure and protocol were used to amplify the $18 \mathrm{~S}$ rRNA gene and the ITS1-5.8S-ITS2 region, except that the primers for the $18 \mathrm{~S}$ rRNA gene were the eukaryotic universal primers (23) A (5'-CCGAATTCGTCGACA ACCTGGTTGATCCTGCCAGT-3') and B (5'-CCCGGGATCCAAGCTTGATCCTTC TGCAGGTTCACCTAC-3') while the ITS4 and ITS5 primers (24) were used to amplify the ITS1-5.8S-ITS2 region. Primers were purchased from Invitrogen/Life Technologies (São Paulo, SP, Brazil).

\section{Cloning}

PCR products were cloned in the pGEM$T$ vector (Promega, Madison, WI, USA), and transformed into competent XL1-BLU $E$. coli cells and recombinant clones selected and purified by a Miniprep procedure (25).

\section{Sequencing}

Both strands of recombinant plasmids or PCR products were individually sequenced with the SequiTherm kit (Epicentre Technologies, Madison, WI, USA) according to manufacturer instructions. Each reaction contained 800 ng of purified DNA and 0.300.35 pmol infrared dye-labeled primer (Epicentre Technologies). The 5.8S-ITS2$28 \mathrm{~S}$ fragments were sequenced using the vector primers M13F (5'-CACGACGTTG TAAAACGAC-3') and M13R (5'-GGATA ACAATTTCACACAGG-3') and the internal primers F-63 (5'-TTCCTCCGCTTAT
TGATA-TGC-3') and R-63 (5'-TTCCTCC GCTTATTGATATGC-3') (Invitrogen/Life Technologies). Reaction conditions included denaturation at $94^{\circ} \mathrm{C}$ for $3 \mathrm{~min}$ followed by 30 amplification cycles of $94^{\circ}, 50^{\circ}$, and $70^{\circ} \mathrm{C}$ for $30 \mathrm{~s}$ each. The same procedure was used for sequencing the $18 \mathrm{~S}$ gene, using the $\mathrm{M} 13 \mathrm{~F}$ and M13R primers as well as the internal primers 514F (5'-TCTGGTGCCAGCASC CGCGG-3'), 536R (5'-TGGWATTACCGC GGSTGCTG-3'), 1055F (5'-GTGGTGGTGC ATGGCCG-3'), and 1055R (5'-AAGAAC GGCCATGCACCAC-3') (26). Reaction products were sequenced on a $\mathrm{Li}-\mathrm{Cor} 4000 \mathrm{~L}$ automated sequencing system (Li-Cor Biosciences, Lincoln, NE, USA). The ITS15.8S-ITS2 amplicons were sequenced using a $10-\mu 1$ reaction mixture containing 6 pmol of the same primers as for their amplification, $100 \mathrm{ng}$ template, $2.5 \mu \mathrm{l}$ Big Dye reactant (product number 4303153, PE Applied Biosystems, Foster City, CA, USA), $2 \mu 1100$ $\mathrm{mM}$ Tris and $2.5 \mathrm{mM} \mathrm{MgCl}_{2}$, $\mathrm{pH}$ 9.0. Reaction conditions included denaturation at $96^{\circ} \mathrm{C}$ for $1.5 \mathrm{~min}$ followed by 25 amplification cycles of $96^{\circ} \mathrm{C}$ for $12 \mathrm{~s}, 50^{\circ} \mathrm{C}$ for $8 \mathrm{~s}$ and $60^{\circ} \mathrm{C}$ for $4 \mathrm{~min}$. Reaction products were sequenced on an ABI 377 automated sequence system (Applied Biosystems).

\section{Sequence analysis}

DNA sequences were aligned using the ClustalW program (27) and compared to each other using the distance values generated according to Jukes and Cantor's substitution model (28) as implemented by the DNADIST program, version 3.5c, contained in the Phylip package (29). Nucleotide diversity $(\pi)$, i.e., the average number of differences per site between two homologous sequences, was calculated using the DnaSP software, version 2.0 (30), according to equation 10.5 of Nei (31). Phylogenetic analysis was carried out using the maximum parsimony method as implemented by the PAUP* software 4.0b4a (32). The median-joining 
network connecting the sequences was constructed using the program Network 3.1.1.1 (available at www.fluxus-engineering.com) and the median joining algorithm (33). Default settings were chosen $(r=2$ and $\varepsilon=0)$.

\section{Results}

In order to assess heterogeneity within and between isolates we sequenced individual clones containing the 5.8S-ITS2-28S amplicon. At least seven clones were sequenced for each fungal isolate. We were especially interested in the ITS regions, which are known to incorporate changes at relatively high rates (see, e.g., 34,35). The $18 \mathrm{~S}$ rDNA, which evolves comparatively slowly, was sequenced using pooled clones of each isolate. The $18 \mathrm{~S}$ and $5.8 \mathrm{~S}-\mathrm{ITS} 2-28 \mathrm{~S}$ se- quences generated are deposited in GenBank under accession numbers AF076380 to AF076430 and the ITS1-5.8S-ITS2 sequences are deposited under accession numbers AY642807 to AY642816.

Few differences were found between isolates $\mathrm{A}$ to $\mathrm{F}$, which were collected from two geographic sites (Table 1) and had identical 1760-bp 18S sequences, the 121-bp 5.8S and 690-bp 28S sequences showing more than $99 \%$ similarity. Variation in the ITS2 region (212 to $218 \mathrm{bp}$ ) was higher, with the 45 sequenced clones containing 15 distinct ITS2 haplotypes which had 25 variable positions corresponding to 7 micro-satellites (1, 2 or 4 base repeats) and 14 transitions $(8 \mathrm{C} /$ $\mathrm{T}$ and $6 \mathrm{~A} / \mathrm{G}$; Figure 2). Nucleotide diversity in the 45 ITS 2 sequenced clones $(\pi=0.00589$ \pm 0.00110 ) was too low to allow population

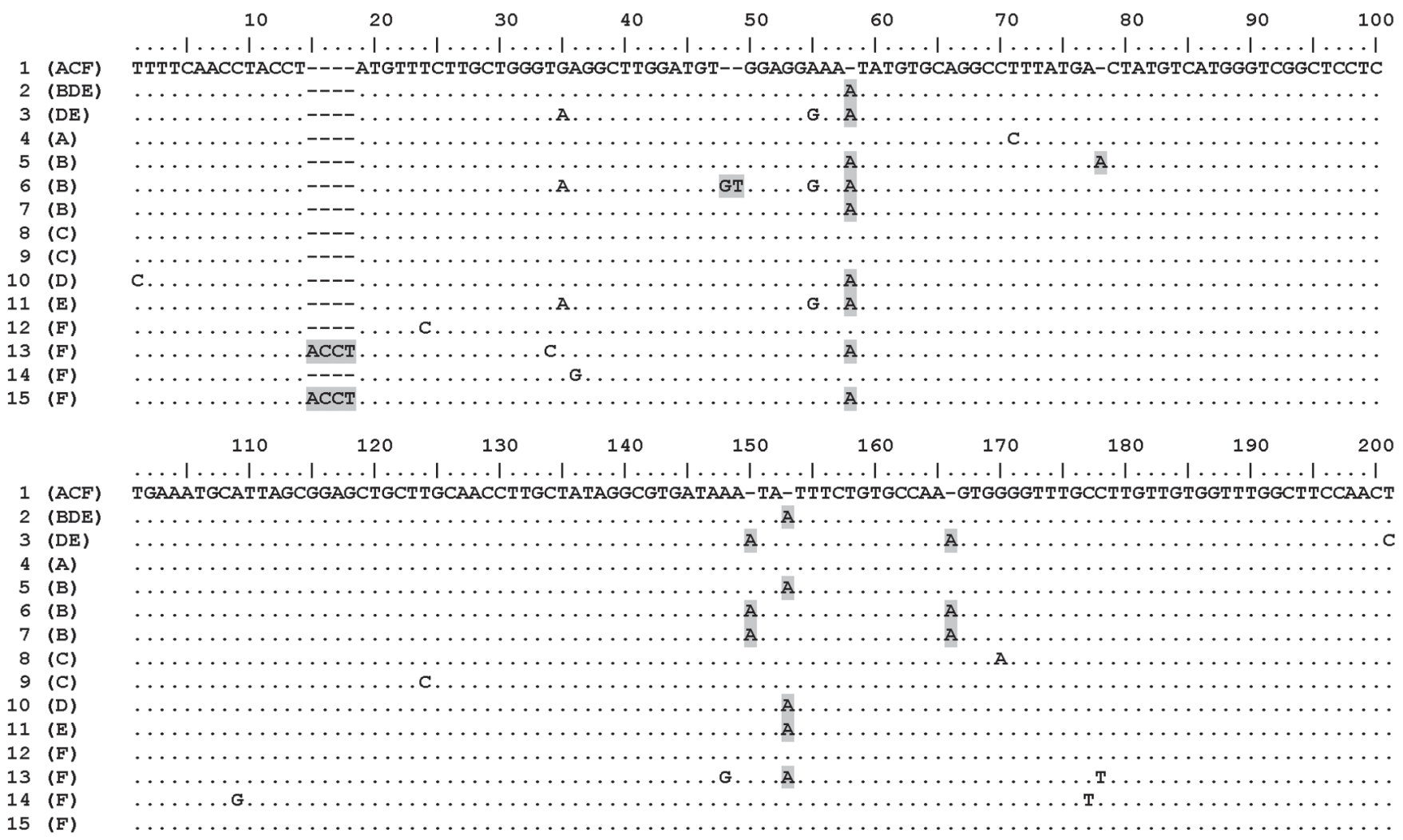

Figure 2. Polymorphic sites of the 15 ITS2 haplotypes of six symbiotic fungal isolates. Fungal isolates were collected from nests of Atta laevigata (A), Atta sexdens rubropilosa (B), Acromyrmex crassispinus (C), Acromyrmex hispidus fallax (D = mycelium, E = basidiocarp), and Atta capiguara (F). The ITS2 region of these isolates contained 212 to 218 bp, of which a 201-bp alignment containing the ITS2 polymorphic sites is represented. Dots indicate conserved sites and letters polymorphic sites, micro-satellite repeats are shaded and transitions are unshaded. Haplotypes are numbered from 1 to 15 and isolates in which a known ITS2 haplotype was found are given within parentheses. 
studies and, similarly, the 2 parsimony-informative characters present in the 14 haplotypes (haplotype 11 was not considered in the parsimony analysis, since isolated $\mathrm{D}$ and $\mathrm{E}$ are from the same source nest) resulted in a highly polytomic tree (data not shown).

Although the information available was insufficient to reveal detailed relationships between our isolates in a phylogenetic tree

Table 2. Distribution and number of hits of each of the 15 ITS2 haplotypes found in the 45 sequenced clones of six sympatric or allopatric fungal isolates from Atta and Acromyrmex leafcutter ants.

Isolate $^{1} \quad$ ITS2 haplotype Total

\begin{tabular}{lllllllllllllll}
\hline 1 & 2 & 3 & 4 & 5 & 6 & 7 & 8 & 9 & 10 & 11 & 12 & 13 & 14 & 15
\end{tabular}

\begin{tabular}{lllllllllllllllll}
\hline $\mathrm{A}$ & $\mathrm{7}$ & - & - & 1 & - & - & - & - & - & - & - & - & - & - & - & 8 \\
$\mathrm{~B}$ & - & 2 & - & - & 3 & 1 & 1 & - & - & - & - & - & - & - & - & 7 \\
$\mathrm{C}$ & 5 & - & - & - & - & - & - & 1 & 2 & - & - & - & - & - & - & 8 \\
$\mathrm{D}$ & - & 4 & 3 & - & - & - & - & - & - & 1 & - & - & - & - & - & 8 \\
$\mathrm{E}$ & - & 4 & 2 & - & - & - & - & - & - & - & 1 & - & - & - & - & 7 \\
$\mathrm{~F}$ & 2 & - & - & - & - & - & - & - & - & - & - & 2 & 1 & 1 & 1 & 7 \\
Total & 14 & 10 & 5 & 1 & 3 & 1 & 1 & 1 & 1 & 1 & 1 & 2 & 1 & 1 & 1 & 45
\end{tabular}

${ }^{1}$ Fungus symbiotic with Atta laevigata (A), Atta sexdens rubropilosa (B), Acromyrmex crassispinus (C), Acromyrmex hispidus fallax ( $\mathrm{D}=$ mycelium, $\mathrm{E}=$ basidiocarp), and Atta capiguara (F). Shaded numbers indicate the number of hits for haplotypes that were shared by distinct isolates.

Figure 3. Phylogenetic relationship between the 15 ITS2 haplotypes of six symbiotic fungal isolates. Network nodes (circles) indicate haplotypes, which are numbered in bold and proportionally sized to the number of sequences they represent, i.e., $1,2,3,5,10$, and 14 sequences. The areas of the colored parts of the circles are proportional to the number of sequence copies from each of the fungal isolates A to $F$ (see also Table 2). Note that haplotypes from fungal isolates $\mathrm{A}, \mathrm{C}$ and $\mathrm{F}$ are, in general, more closely related to each other than to haplotypes from isolates $\mathrm{B}, \mathrm{D}$ and $\mathrm{E}$.

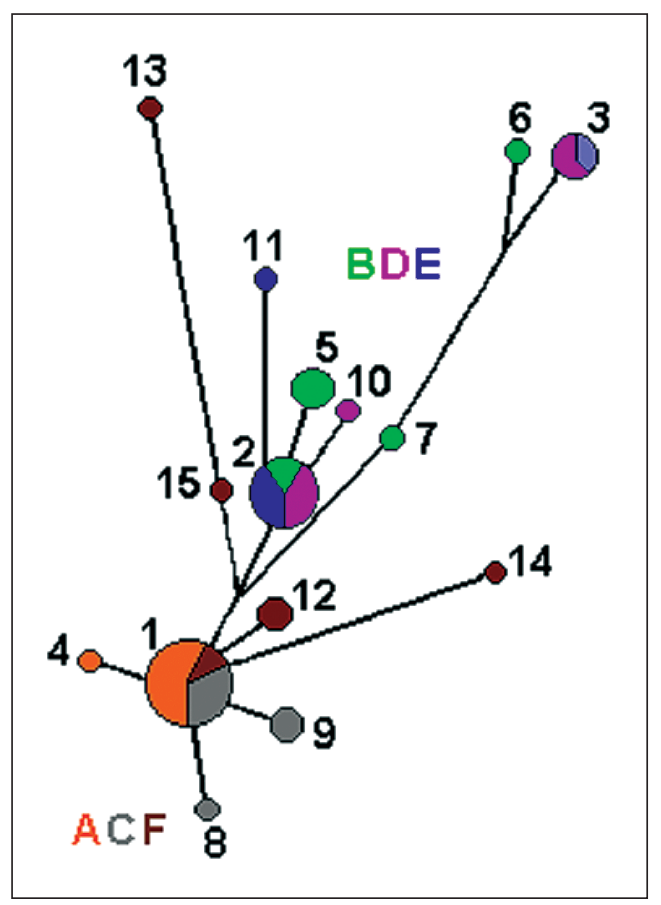

or to support a population study of these isolates, it was possible to group them by considering the three ITS2 haplotypes which were shared by several isolates (Table 2). The distribution of the shared haplotypes suggests that leafcutter fungal isolates $\mathrm{A}$ to $\mathrm{F}$ belong to two genetic groups, one group being composed of isolates A (from Atta laevigata), C (from Acromyrmex crassispinus) and F (from Atta capiguara), all containing ITS2 haplotype 1 but not haplotype 2 , and the other group containing isolate B (from Atta sexdens rubropilosa) and isolates D and E (both from Acromyrmex hispidus fallax), all containing ITS2 haplotype 2 but not haplotype 1. Fungal isolates $\mathrm{D}$ and $\mathrm{E}$ also shared ITS2 haplotype 3. A phylogenetic network derived by the median-joining method showed that haplotypes 1 and 2 are likely centers of radiation/convergence of the ACF and BDE groups, respectively, so that some haplotypes are more closely related within the ACF (haplotypes 1, 4, 8, 9, $12,14)$ or BDE (haplotypes 2, 5, 10, 11) groups than between groups, although haplotypes $3,6,7,13$, and 15 were equally related to both $\mathrm{ACF}$ and $\mathrm{BDE}$ groups (Figure $3)$. These results suggest that the ACF and BDE genetic groups are in fact two distinct lineages of symbiotic fungi.

To extend our observations to a wider geographic region and other ant species, we investigated fungal isolates $\mathrm{G}$ to $\mathrm{O}$ (Table 1), collected from the nests of seven leafcutter species living in five different geographic sites. Both ITS1 and ITS2 regions were analyzed by sequencing the amplified ITS15.8S-ITS2 fragments, but few polymorphic positions were found in the first clones obtained from isolates $\mathrm{K}$ and $\mathrm{N}$. Because of this we decided to directly sequence the PCR products of isolates $\mathrm{E}$ and $\mathrm{G}$ to $\mathrm{O}$ and found them to be identical or to differ by only a maximum distance of $1.5 \%$, in contrast to the 6.7 to $26 \%$ distance found between the 10 most closely related sequences of the GenBank Leucoagaricus species (see spe- 
cies names in Figure 4).

Similarly, the distance between the ITS2 regions of isolates $\mathrm{A}$ to $\mathrm{O}$ was zero to $2.5 \%$, while the distance between the ITS2 regions of the 10 most closely related GenBank Leucoagaricus isolates was 9.4 to $26 \%$. In addition, the ITS1 locus presented a highly variable portion that had a base composition and sequence length characteristic for each of the GenBank 10 Leucoagaricus species investigated. Conversely, this region was identical for our leafcutter isolates $\mathrm{E}$ and $\mathrm{G}$ to $\mathrm{O}$ (Figure 4). These results indicate that the leafcutters studied by us cultivate very closely related fungal material, probably the same species, over a wide geographic region.

\section{Discussion}

In the past it has been difficult to demonstrate that a basidiocarp found in Atta or Acromyrmex nests is that of the ant's symbiotic fungus and not one of the many contaminant fungi existing in the nests (36). This situation has led to uncertainties in the identification of ant fungi, which have received over a dozen names $(4,37,38)$.

In our investigation we found that the Leucoagaricus gongylophorus basidiocarp (E in Table 1) and the mycelial isolate (D in Table 1), both collected from the same Acromyrmex hispidus fallax nest, had two identical (and some nearly identical) ITS2 sequences (Table 2). Since ITS regions have been used to distinguish species of fungi (e.g., 39) our results suggest that this Leucoagaricus gongylophorus basidiocarp represents the sexual stage of the symbiotic fungus of Acromyrmex hispidus fallax, supporting our previous results showing identical RAPD fingerprints for these two isolates (22).

The Leucoagaricus gongylophorus basidiocarp was also found to have ITS2 sequences which were identical, or nearly identical, to those of mycelial isolates from the nests of Atta laevigata (isolate A), Atta sexdens rubropilosa (isolate B) and Acromyrmex crassispinus (isolate $\mathrm{C}$ ), all sympatric leafcutter species collected near the town of Rio Claro, SP, as well as to fungal isolate F collected from an Atta capiguara nest near the town of Botucatu, SP, $105 \mathrm{~km}$ from Rio Claro, and other fungal symbionts (isolates $\mathrm{G}$ to $\mathrm{O}$ ) from sites near the towns of Botucatu, Ubatuba, Viçosa, and Almeirim, which are up to $2,600 \mathrm{~km}$ apart from each other. The variations found in these ITS2 sequences were very low compared to those of GenBank ITS2 sequences belonging to 10 distinct $\mathrm{Leu}$ coagaricus species. In addition, the highly variable portion of ITS1, which contains a characteristic signature for each Leucoagaricus species, was identical in 10 of our fungal symbionts (isolates $\mathrm{E}$ and $\mathrm{G}$ to $\mathrm{O}$ ) living in each of the investigated sites.

Taken together, these results indicate that the sympatric and allopatric leafcutter species studied in the present investigation are associated with closely similar fungal material, which may represent a single Leucoagaricus species, suggesting that leaf-cutting ants cultivate the same fungal species over a wide geographic region of South America and indicating that the 'single species theory' regarding fungal culture by

10 20

I. americanus

I. bresadolae

I. crystallifer

I. hortensis

I. marriagei

I. naucinus

I. purpureolilacinus

I. sereneus

I. sericifer

I. wychanskyi

I. gongylophorus E, G-O ........TCA..T.GA.GTG..TT

Figure 4. Characteristic signature for each Leucoagaricus species. Representation of the portion of the ITS1 sequence that was highly variable in Leucoagaricus species but identical in ten fungal isolates collected from eight leafcutter species living in five geographic sites. Dots represent the conserved sites and letters the polymorphic sites of the ITS1 sequences compared to Leucoagaricus americanus. The accession numbers of the GenBank Leucoagaricus sequences were LAU85317, AF295929, AF482863, AF482843, AF482866, LNU85315, AF482869, AF482871, AF482872, AF482874 (in order from the top to the bottom of the figure). 
leafcutters is more likely than the 'multiple species theory'. Therefore, it is likely that the Leucoagaricus gongylophorus basidiocarp (E in Table 1) represents the sexual stage of all the mycelial state isolates studied in the present investigation.

The degree of polymorphism that we found in the ITS sequences was too low to reveal detailed relationships between our isolates in a phylogenetic tree. However, distribution of ITS sequences within our fungal isolates collected from the Rio Claro or Botucatu areas suggests that these isolates belong to distinct genetic groups characterized by a specific ITS2 haplotype (Table 2), haplotype 1 only being found in isolates $\mathrm{A}, \mathrm{C}$ and $\mathrm{F}$ (14 hits in 23 sequenced clones) and haplotype 2 only in isolates $\mathrm{B}, \mathrm{D}$ and $\mathrm{E}$ (10 hits in 22 sequenced clones). These results, as well as the phylogenetic relationship between haplotypes derived by median-joining analysis (Figure 3), suggest that these two genetic groups are in fact two distinct fungal lineages. Thus, it seems that the fungal strains cultured by Atta laevigata, Acromyrmex crassispinus and Atta capiguara (belonging to the ACF lineage) are more similar to each other than they are to the fungal strains cultured by Atta sexdens rubropilosa and Acromyrmex hispidus fallax (BDE lineage). Chapela et al. (10) hypothesized that there has been restricted vertical transmission of symbiotic fungi in the higher attines for the last 23 million years, which suggests that the symbiotic fungi of Atta ants should be more similar to each other than they are to the symbiotic fungi of Acromyrmex ants. However, our findings do not support the exclusively vertical transmission of symbiotic fungi in higher attines, suggesting instead that lateral transmission may occur under certain circumstances.

Our findings are supported in part by those of Bot et al. (18), who found that, in Panama, lateral transmission of fungal material may have occurred between the sympatric species Acromyrmex octospinosus and
Acromyrmex echinatior. However, these investigators also mention that lateral transfer of symbiotic fungi between Atta and Acromyrmex ants does not occur, although our results show that some Atta and Acromyrmex species do indeed cultivate the same lineage of Leucoagaricus gongylophorus and hence have probably recently shared their symbiotic fungi.

Markers may exist, which are evolving faster than the ITS regions, and their sequences would provide more polymorphic sites and suitable information for population studies, so that detailed information on the propagation of Leucoagaricus gongylophorus lineages throughout distinct leafcutter nests could be assessed. Such propagation seems to be a general characteristic within leafcutters, considering the evidence that we found for lateral transmission of fungal material within the ants from Rio Claro and Botucatu, in Brazil, as well as similar evidence described for some Panamanian Acromyrmex (18). Thus, it is conceivable that during the symbiosis evolution a continuous sharing of fungal strains has often occurred and has led to the homogenization of the symbiotic fungal stock through the selection of the Leucoagaricus gongylophorus lineages found in both the sympatric and allopatric leafcutters sampled in our study. This scenario of intense lateral transmission of fungal material between leafcutters is consistent with the low variation in both ITS1 and ITS2 found in our isolates and resembles the 'mycocentric' view of the ant-fungus symbiosis that was recently pointed out by Mueller (40), who suggested that symbiotic fungi may play a dominant part in the antfungus association. This point of view stands in contrast with the traditional 'myrmicocentric' view of the ant-fungus symbiosis in which the fungus has the passive role of a mere cultivated crop that is manipulated by the ants according to their needs. The symbiotic fungus, Leucoagaricus gongylophorus, may be transferred by leafcutters directly 
from one nest to another or, conversely, this transmission may involve an intermediary free-living fungal stage so that many clones of the original symbiotic fungus could have been spread over the period of time during which these ants have been living in America. Thus, it is possible that free-living close relatives (or even free-living forms) of $\mathrm{Leu}$ coagaricus gongylophorus exist.

In addition to intensive lateral transmission, some features of symbiotic fungal lineages may have shaped the population structure of Leucoagaricus gongylophorus, such as resistance to antibiotics produced either by the ants (40) or the actinomycete symbiont or to the parasite Escovopsis, so that more adapted fungal strains may have been selected. Thus, the complete elucidation of the factors that have led to the low variation in Leucoagaricus gongylophorus ITS sequences requires an intensive sampling and characterization of the two groups of symbiotic microorganisms of many leafcutters from distinct geographic sites in America.

\section{Acknowledgments}

Dr. Fábio O. Freitas (Embrapa-Cenargem, Brasília, DF, Brazil) is acknowledged for his comments on median-joining analysis and Dr. Ulrich G. Mueller (The University of Texas, Austin, TX, USA) is also acknowledged for his comments on earlier versions of this paper.

\section{References}

1. Currie CR, Wong B, Stuart AE, Schultz TR, Rehner SA, Mueller UG, Sung GH, Spatafora JW \& Strauss NA (2003). Ancient tripartite coevolution in the attine ant-microbe symbiosis. Science, 299: 386388.

2. Bolton B (1995). A New General Catalogue of the Ants of the World. Harvard University Press, Cambridge, MA, USA.

3. Brandão CFR \& Nunes AM (2001). A new fungus-growing ant genus Mycetagroicus gen. $n$., with the description of three new species and comments on the monophyly of the Attini (Hymenoptera: Formicidae). Sociobiology, 38: 639-665

4. Weber NA (1979). Fungus culturing by ants. In: Batra LR (Editor), Insect-Fungus Symbiosis, Mutualism and Commensalism. 20th International Mycological Congress, Tampa, FL, USA. Halsted Press, New York, 77-115.

5. Hölldobler B \& Wilson EO (1990). The Ants. The Belknap Press of Harward University Press, Cambridge, MA, USA.

6. Martin MM (1970). The biochemical basis of the fungus-attine ant symbiosis. Science, 169: 16-20.

7. Bass M \& Cherrett JM (1995). Fungal hyphae as a source of nutrients for the leaf-cutting ants Atta sexdens. Physiological Entomology, 20: 1-6.

8. North RD, Jackson CW \& Howse PE (1997). Evolutionary aspects of ant-fungus interactions in the leaf-cutting ants. Trends in Ecology and Evolution, 12: 386-389.

9. Siqueira CG, Bacci M, Pagnocca FC, Bueno OC \& Hebling MJA (1998). Metabolism of plant polysaccharides by Leucoagaricus gongylophorus, the symbiotic fungus of the leaf-cutting ant Atta sexdens L. Applied and Environmental Microbiology, 64: 4820-4822.

10. Chapela IH, Rehner SA, Schultz TR \& Muller UG (1994). Evolutionary history of the symbiosis between fungus-growing ants and their fungi. Science, 266: 1691-1694.

11. Hinkle G, Wetterer JK, Schultz TR \& Sogin ML (1994). Phylogeny of the attine fungi based on analysis of small subunit ribosomal RNA gene sequences. Science, 226: 1695-1697.
12. Bononi VLR, Autuori M \& Rocha MB (1981). Leucocoprinus gongylophorus (Möller) Heim, o fungo do formigueiro de Atta sexdens rubropilosa Forel. Rickia, 9: 93-97.

13. Fisher PJ, Stradling DJ \& Pegler DN (1994). Leaf cutting ants, their fungus gardens and the formation of basidiomata of Leucoagaricus gongylophorus. Mycologist, 8: 884-888.

14. Muchovej JJ, Della Lucia TM \& Muchovej RM (1991). Leucoagaricus weberi sp nov. from a live nest of leaf-cutting ants. Mycological Research, 95: 1308-1311.

15. Stradling DJ \& Powel RJ (1986). The cloning of more highly productive fungal strains: a factor in the speciation of fungus growing ants. Experientia, 42: 962-964.

16. Weber NA (1972). Gardening ants, the attines. Memoirs of the American Philosophical Society (Philadelphia, PA, USA), 92: 1-146.

17. Adams RMM, Mueller UG, Holloway AK, Green AM \& Narozniak J (2000). Garden sharing and garden stealing in fungus-growing ants. Naturwissenschaften, 87: 491-493.

18. Bot ANM, Rehner SA \& Boomsma JJ (2001). Partial incompatibility between ants and symbiotic fungi in two sympatric species of Acromyrmex leaf-cutting ants. Evolution, 55: 1980-2001.

19. Mueller UG, Lipari SE \& Milgroom MG (1996). Amplified fragment length polymorphism (AFLP) fingerprinting of symbiotic fungi cultured by the fungus-growing ant Cyphomyrmex minutus. Molecular Ecology, 5: 119-122.

20. Mueller UG, Rehner SA \& Shultz TR (1998). The evolution of agriculture in ants. Science, 281: 2034-2038.

21. Green AM, Adams RMM \& Mueller UG (2002). Extensive exchange of fungal cultivars between sympatric species of fungus-growing ants. Molecular Ecology, 11: 191-195.

22. Pagnocca FC, Bacci M, Fungaro MH, Bueno OC, Hebling MJA, Sant'anna A \& Cappellari M (2001). RAPD analysis in basidiomata found in a nest of the leaf-cutting ant Acromyrmex hispidus fallax, Santschi. Mycological Research, 105: 173-176.

23. Medlin L, Elwood HJ \& Stickel S (1988). The characterization of 
enzymatically amplified eucaryotic 16S-like rRNA coding regions. Gene, 71: 491-499.

24. White TJ, Bruns T, Lee S \& Taylor J (1990). Amplification and direct sequencing of fungal ribosomal RNA genes for phylogenetics. In: Innis MA, Gelfand DH, Sninsky JJ \& White TJ (Editors), PCR Protocols: A Guide to Methods and Applications. Academic Press, San Diego, CA, USA, 315-322.

25. Sambrook J \& Russel DW (2001). Molecular Cloning: A Laboratory Manual. 3rd edn. Cold Spring Harbor Laboratory Press, Cold Spring Harbor, New York.

26. Elwood HJ, Olsen GH \& Sogin ML (1985). The small-subunit ribosomal RNA gene sequences from the hypotrichous ciliates Oxytricha nova and Stylonychia pustulata. Molecular Biology and Evolution, 2: 399-410.

27. Thompson JD, Higgins DG \& Gibson TJ (1994). CLUSTAL W: improving the sensitivity of progressive multiple sequence alignment through sequence weighting, position specific gap penalties and weight matrix choice. Nucleic Acids Research, 22: 4673-4680.

28. Jukes TH \& Cantor CR (1969). Evolution of protein molecules. In: Munro HN (Editor), Mammalian Protein Metabolism III. Academic Press, New York.

29. Felsenstein J (1989). PHYLIP - Phylogeny Inference Package (Version 3.2). Cladistics, 5: 164-166.

30. Rozas J \& Rozas R (1997). DnaSP version 2.0: a novel software package for extensive molecular populational genetic data analysis. Computer Applications in the Biosciences, 13: 307-311.

31. Nei M (1988). Molecular Evolutionary Genetics. Columbia University Press, New York.
32. Swofford DL (2000). Phylogenetic Analysis Using Parsimony, Version 4.0b4a. Illinois Natural History Survey, Champaign, IL, USA.

33. Bandelt HJ, Forster P \& Röhl A (1999). Median-joining networks for inferring intraspecific phylogenies. Molecular Biology and Evolution, 16: $37-48$.

34. O'Donnel K (1992). Ribosomal DNA internal transcribed spacers are highly divergent in the phytopathogenic ascomycete Fusarium sambucinum (Giberella pulicaris). Current Genetics, 22: 213-220.

35. Campbell AJD, Gasser RB \& Chilton NB (1995). Differences in a ribosomal DNA sequence of Strongylus species allow identification of single eggs. International Journal of Parasitology, 25: 359-365.

36. Fisher PJ, Stradling DJ, Sutton BC \& Petrini LE (1996). Microfungi in the fungus gardens of the leaf-cutting ant Atta cephalotes: a preliminary study. Mycological Reserch, 100: 541-546.

37. Wetterer JK (1994). Nourishment and evolution in fungus-growing ants and their fungi. In: Hunt JH \& Nalepa CA (Editors), Nourishment and Evolution in Insects Societies. Westview Press, Bolder, CO, USA.

38. Kermarrec A, Decharme M \& Febvay G (1986). Leaf-cutting ant symbiotic fungi: a synthesis of recent research. In: Lofgren CS \& Van der Meer RK (Editors), Fire Ants and Leaf-Cutting Ants. Westview, Bolder, CO, USA and London, UK.

39. Sreenivasaprasad S, Mills PR, Meeham BM \& Brown AE (1996). Phylogeny and systematics of 18 Colletotrichum species based on ribosomal RNA spacer sequence. Genome, 39: 499-512.

40. Mueller UG (2002). Ant versus fungus versus mutualism: Ant-cultivar conflict and the deconstruction of the attine ant-fungus symbiosis. American Naturalist, 160: S67-S98 